\title{
Phlebitis Infective, CTCAE
}

National Cancer Institute

\section{Source}

National Cancer Institute. Phlebitis Infective, CT CAE. NCI Thesaurus. Code C143760.

A disorder characterized by an infectious process involving the vein. Clinical

manifestations include erythema, marked discomfort, swelling, and induration along the course of the infected vein. 